\title{
A Quantitative View on Policymakers' Goal, Institutions and Tax Evasion
}

\author{
Maurizio Bovi ${ }^{\dagger} \&$ Roy Cerqueti** \\ ${ }^{\dagger}$ Italian National Institute of Statistics (ISTAT). \\ Piazza dell'Indipendenza, 4, 00185, Rome, Italy.
}

Tel.: +39 06 44482754; fax: +39 06 44482249. Email: mbovi@istat.it.

$\ddagger$ University of Macerata, Department of Economics and Law.

Via Crescimbeni 20, 62100, Macerata, Italy.

Tel.: +39 0733 2583246; fax: +390733 2583205. Email: roy.cerqueti@unimc.it

\begin{abstract}
We develop a general theoretical model to compare two different policymakers both facing tax evasion. Policymakers differs in that they aim to maximize either the fiscal revenues $(T)$ as in a social-democracy as, e.g., Sweden, or the GDP as in a capitalistic country as, e.g., the USA. Both Bureaus can manoeuvre the tax rate and the share of tax receipts spent to fight the tax evasion rather than to increase the public capital. Our model merges the indications of two distinct, and sometimes conflicting, approaches to the analysis of tax evasion in that reconciling them. We also find that the feedbacks between the private and public sector are linked to some Laffer-type relationships usually unexplored by the existing literature. As compared to capitalistic systems, then, our results show that social-democracies end up imposing higher tax rates and, possibly, more pervasive regulations. Consequently, they are likely to suffer from larger tax-evasion-to-GDP ratios. This notwithstanding, social-democracies spend relatively more to contrast tax dodgers. On the other hand, $T$-maximizing governments have better institutional settings

\footnotetext{
${ }^{*}$ Corresponding author
} 
and greater employment rates. Whichever the preferred target, however, no policymaker is able to erase totally the tax evasion, which may explain why this latter is so pervasive and persistent even among the richest countries.

JEL Code: D73, H26, O17

Keywords: Quantitative model, Bureaucracy, Tax evasion, Regulations, Taxation.

\section{Introduction}

A well-known anecdote states that tax evasion is as old as taxation. By the same token one may also add that since taxation is as old as State, the same can be said for the tax evasion. In the words of Klepper and Nagin (1989, p.1) "Three things are certain in life: death, taxes, and mankind's unrelenting effort to evade both.". The spiral "higher tax rates, higher tax evasion" is cited as one of the main reasons why the Roman Empire fell (Bernardi, 1970). More recently, according to the cross section evidence collected by La Porta and Shleifer (2008), the share of tax evasion on official GDP varies, to mention the most conservative figures, from almost $30 \%$ in poorest countries to up $8 \%$ in richest economies. Otherwise stated, the tax evasion is an immanent fact of life around the world.

The shadow economy ${ }^{1}$ has some positive effects. For instance, it provides an alternative social safety net and may be the necessary first-step for training the new firms. This said, in both political and economic circles it is usually seen more as a problem than as a resource, and "zero-tolerance" announces are commonly heard. The presence of hidden activities, in fact, may affect the design of national tax systems and trigger links between legal and illegal activities. It may then impose constraints on public revenues generation and, therefore, limit the provision of necessary public goods/services. Moreover, e.g. due to unfair competition, shadow activities are likely to hamper the GDP. Finally, it has been observed a strong positive correlation between tax morale and institu-

\footnotetext{
${ }^{1}$ While the shadow (unofficial, irregular...) economy takes many forms -e.g., illegal activities, unreported income (tax evasion) and the informal sector- the focus of this paper is the tax evasion.
} 
tional quality (Frey and Torgler, 2007; Hug and Spörri, 2011).

The pervasiveness and persistence of the tax evasion side-by-side with better and better anti-evasion technology and worldwide zero-tolerance announces suggests to examine i) why the phenomenon is so hard to eradicate practically in all economic environments and, accordingly, ii) its effects in different economic systems.

In this paper, we attempt to shed some light on these issues by developing a general equilibrium model aimed at examining the theoretical links between tax evasion, macro policies and institutions. Specifically, we study the persistence and the effects of the tax evasion when policymakers pursue two alternative macroeconomic targets, namely maximizing fiscal revenues $(\mathrm{T})$ or the GDP. The logic of this clear-cut in policymakers' goal is to more easily compare these two distinct situations which, by and large, can be thought of as representative of, respectively, social-democracy and capitalism. Thus, our analysis can also be useful for the understanding of what a developing or transition country may expect to face should it follow a social-democratic rather than a capitalistic road to develop. On the other hand, anticipating one of our results, we find that governments cannot be revenues- and GDP-maximizers at the same time so that a political dilemma emerge. Though this is a somewhat expected outcome, as far as we know ours is the first model to formalize it. Even more so because ours is a general equilibrium framework. In building our model we have borrowed from both the portfolio choice tradition (Allingham and Sandmo, 1972; Yitzhaki, 1974 and followers) and the recent institutional approach (Johnson et al., 1998 and 1999). As we will say, these strands of research have different views about the sign of the correlation linking tax rate and tax evasion. Therefore, our model allows to reconcile this dissonance. We have also opted to keep the model rather general. The idea is that the abstractness of our setting avoids limiting the study to a peculiar analytical setting. In fact, we can afford to not rely on explicit functions for the parameters which, as e.g. in the case of variables describing the institutional setting, may turn out to be tricky. The generality of the setting means that our model nests several specifications and, accordingly, it is very robust.

Other contributions of our paper that we want to stress are the following. Com- 
paring two different economic systems - such as, say, Sweden and the USA with a special focus on tax evasion allows us to uncover and discuss some new Laffer-type non linearities. These latter come from the feedbacks between the private and public sector and are typically neglected in the existing literature (Section 2). Then, we offer a theoretical framework that could help to better understand the empirical findings reported by several papers often based on just sketched theoretical considerations (see, e.g., Friedman et al., 2000 and Johnson et al., 1999 just to mention two papers dealing with the set of variables here under scrutiny). In fact, given the easy-to-imagine data problems affecting variables such as tax evasion, institutional efficiency, etc. (low quality, reduced time series and cross section comparability, etc.,), our conceptual robust setting can act like a map that gives coherence to empirical inquiry.

Side by side with the mentioned policy dilemma, other results stem from our analysis. As compared to GDP-maximizing states, social-democracies tend to impose higher tax rates, more pervasive regulations and, consequently, to suffer from larger tax-evasion-to-GDP ratios. All this in spite of the fact that social-democracies spend relatively more to contrast tax dodgers than capitalistic countries. On the other hand, revenues maximizing governments can afford to have better institutional settings and greater participation rates. In no case, however, the Bureau is able to erase totally the tax evasion, which may explain why this latter is so pervasive and persistent all around the world.

The rest of the paper is organized as follows. Section 2 briefly reviews some literature related to our topic. Section 3 contains the constitutive elements of the theoretical model. Section 4 and 5 deal with the optimization problems of the private sector and the State, respectively. In section 6 the theoretical findings are discussed with a focus on two representative cases. Some supporting evidence is also presented. The last section collects concluding remarks. The proofs of the main results are reported in the Appendix.

\section{A Brief Literature Review}

Despite its sheer magnitude and ever-lasting presence, the macroeconomic consequences of tax evasion on revenues and, especially, on output loss, has received 
relatively little attention. As for public revenues loss, in a simple Keynesian model, Peacock and Shaw (1982) were the first to show that, provided the marginal net propensity to spend is less than unity, tax evasion decreases the tax revenue. In a more general framework, Ricketts (1984) confirms the negative effect of tax evasion upon the tax revenue. Years later, Lai and Chang (1988), Von Zameck (1989), and Lai et al. (1995) showed that tax evasion may even lead to an increase in the tax revenue. A common problem with these papers is the lack of microfoundations. More recently, Turnovsky and Basher (2008) have developed a microfounded two-sector model and have examined the role of the informal sector in limiting the governments ability to increase tax revenues. As for more direct links between growth and tax evasion, Caballé and Panadés (2000) have analyzed how the tax compliance policy affects the rate of economic growth. They consider a microfounded overlapping generations model in which the paths of all the involved macroeconomic variables are endogenously determined and perform comparative statics analyses of changes in both the probability of inspection and the penalty fee imposed on tax evaders. They show the nonoptimality from the growth viewpoint of an inspection policy inducing truthful revelation of income for exogenously given levels of both the penalty and the tax rates. Alike, Chen's (2003) microfounded model of endogenous growth has inquired into the effects of three government policies on tax rate, tax evasion, and economic growth. These three policies are as follows: increasing the unit cost of tax evasion, raising punishment and fines, and increasing the probability of detection. He finds that the three policies are quantitatively effective in discouraging tax evasion, but have small growth effects. These latter increase when the public capital has very strong positive externalities. Ihrig and Moe (2004) have analized a simple dynamic model of an agent who chooses to allocate time between the formal and informal sector while accounting for taxation policies. They argue that their model explain why, as an economy grows from a low level of real GDP per capita, changes in informal employment are large. From the normative standpoint these authors suggest that while reductions in the tax rate, combined with increased enforcement, reduce the size of the informal sector, tax rate reductions and penalties for evasion are the most effective. Another strand of research (Johnson et al., 1998 and 1999; Friedman et al., 
2000) has been pointing out the role of institutions in explaining the presence/influence of the tax evasion in/on economic systems. Basically, it argues that the efficiency of the public sector is connected with the tax evasion because the low quality of bureaucracy reduces the probability to detect tax dodgers and this increases, other things being equal, the optimal share of hidden income chosen by agents. In turn, this stops achieving sufficient revenues to fund good institutions. Furthermore, bad governments offer low quality and insufficient public services, making people less willing to pay for them and more willing to search for alternative, hidden, service networks. ${ }^{2}$. These studies underline that another stable equilibrium, opposite to the bad one, is possible. This is why this "institutional" literature is sometimes referred to as the two-equilibria framework. Rich countries cluster in this second polar situation, which can be labeled "good equilibrium" because small hidden sectors, large fiscal revenues, high tax rates and honest/appreciated institutions consistently coexist. Thus, in sharp contrast with the Allingham and Sandmo (1972) traditional result, tax rate and tax evasion may be negatively related. Yet, recently Bovi and Dell'Anno (2010), focusing exclusively on good equilibria, have found empirical evidence that tax rate and tax evasion are significantly positively related. ${ }^{3}$

Other papers establishing multiple equilibria are those of Myles and Naylor (1996), Rosser et al. (2003) and Cule and Fulton (2009). Myles and Naylor (1996) develop a social custom and conformity model of tax evasion and obtain two equilibria: one with no evasion and one with total evasion. According to Rosser et al. (2003), then, the returns to labor of participating in shadow activities are increasing for a while as the relative size of the hidden sector increases and then decrease beyond some point. This can create a critical threshold that can generate two distinct stable equilibrium states, one with a small underground sector and one with a large underground sector. Finally, in Cule and Fulton (2009) the source of the multiple equilibria is the externalities created

\footnotetext{
${ }^{2}$ This spiral is in line both with the results of Hanousek and Palda (2004), and with the observed strong positive correlation between tax morale and institutional quality (Frey and Torgler, 2007).

${ }^{3}$ In fact, in a sub sample analysis targeted to richer countries, even Friedman et al., (2000) did not find evidence against the traditional positive correlation between tax rate and tax evasion. Results by Pommerehne and Weck-Hannemann (1996) support the positive correlation.
} 
by business and tax inspection cultures. Specifically, in bad equilibria (high cheating and corruption), increases in penalties or auditing can have perverse impacts and increase cheating. Somewhat mirroring the institutional literature these papers deal especially with bad equilibria, whereas the tax evasion is likely to be persistent.

\section{The Theoretical Framework}

In building our model we have borrowed from both the portfolio choice tradition (Allingham and Sandmo, 1972; Yitzhaki, 1974 and followers) and the recent institutional approach. Our aim is to study the tax-evasion-related links between these two agents when the Bureau is either GDP- or revenues-maximizing. In our model there are two players, a representative private agent and the government. The former solves standard consumption-leisure optimization problems, with the exception that she may hide some income. It is worth noticing that, should the representative agent hide or declare all of her income, the economic system would be, respectively, totally under- or totally overground. As we will see, our model enables the informal sector to remain part of the economy in equilibrium. Since, mature or not, data inform that all economic systems have shadow sectors, the mixed equilibrium is consistent with empirical observations. The optimal share of tax evasion chosen by individuals is constrained by the expected penalty and tax evasion-related costs (e.g., sheltering efforts. See Cross and Shaw, 1982). As in Barro (1990), the private sector benefits from public capital.

In order to maximize either fiscal receipts or the GDP, the State decides the tax rate and the share of public outlay devoted to fight the tax evasion rather than to increase the public capital. ${ }^{4}$ These two goals should be seen as representative of the policies usually implemented, respectively, in mature social-democratic (say, Sweden) and capitalistic (say, the USA) countries. Several Laffer-type relationships emerge in our context.

Beyond the usual mnemonic $L$ (labor input), $Y$ (output), $G$ and $T$ (respectively,

\footnotetext{
${ }^{4}$ The term "public capital" contains all the growth-enhancing items potentially available for policymakers.
} 
public outlays and revenues), throughout the paper we will use the following notations:

- $r \in[0,1]$ is the probability to detect a tax dodger ${ }^{5}$

- $t \in[0,1]$ is the tax rate;

- $y \in[0,1]$ is the share of undeclared income on total income;

- $e$ is an index that measures the level of regulations. For homogeneity, $e$ is assumed to vary between $[0,1]$ with $e=0$ indicating the case of no regulation (disorder), and $e=1$ the case of totally regulated economy (dictatorship);

- $\alpha \in[0,1]$ is the share of the public expenditure $G$ spent to increase $r$. It represents the fraction of public money directly devoted to fight the tax evasion. ${ }^{6}$ This kind of outlay should be meant as comprehensive of both "sticks", e.g. providing for tax inspectors, and "carrots", e.g. reducing the complexity of the tax system. Instead, $1-\alpha$ is the fraction of $G$ devoted to increase/improve the public capital, the only other outlay available for policymakers. As in Barro (1990), we assume that public capital has positive external effects on GDP.

For simplicity, in our model $T=G$ and we define $r$ as an increasing continuous function of $\alpha$ that we will write as $r=r(\alpha)$. Therefore, $r$ is invertible, i.e. there exists a function $p$ such that:

$$
r(\alpha)=\tilde{r} \quad \Leftrightarrow \quad \alpha=p(\tilde{r}) .
$$

It is important to note since now that good institutions (i.e. those with both large $r$ and, as we will see, $\alpha$ ) can afford to collect and, in turn, to spend, large amounts of revenues. Accordingly, despite their relatively lower $1-\alpha$, good institutions have higher levels of public capital than bad ones.

\footnotetext{
${ }^{5}$ Our model examines the situation in which, ex post, tax dodgers are not detected but, ex ante, there is a probability $r>0$ that this happens. Consequently, though taxpayers take into account the expected penalty in their optimization problem, no evader actually pays the penalty. It turns out that the State collects no money via penalties. Considering this extra gain, however, just complicates the model leaving our conclusions unaffected.

${ }^{6}$ For a paper focusing on this topic see Slemrod and Yitzhaki (1987) and Mayshar, 1991.
} 
Following both traditional and institutional approaches, we argue that the share of undeclared income depends on $t, e, r$ :

$$
y=y(t, e, r) .
$$

In our context regulations can be thought of as the level of social control of business (Glaeser and Shleifer, 2003). From the taxpayer's standpoint fulfilling regulations is costly and, therefore, they can be thought of as a tax in disguise. As a consequence, regulations affect positively the share of tax evasion. As we shall explain in Section 5, the Bureau cannot afford to freely manage the level of regulations. This is why we do not put regulations among the policymakers' instruments. The output $Y$ depends on labor input and on $\alpha$

$$
Y=g(L, \alpha)
$$

Detailed comments on this function are collected in the next section.

\section{The Private Sector}

Households maximize their utility, under the budget constraint, pinning down both the optimal share of undeclared income $\left(y^{*}\right)$, and the optimal quantity of labor $\left(L^{*}\right)$. The utility function of the private sector depends on $L$ and $C$, and can be defined as $U(L, C)$. $U$ satisfies the usual properties:

$$
\frac{\partial U(L, C)}{\partial C}>0 ; \frac{\partial U(L, C)}{\partial L}<0 .
$$

The consumption function depends on $y, Y$ and $t$, it is defined as $C(t, y, Y)$ and, obviously:

$$
\frac{\partial C(t, y, Y)}{\partial y}>0 ; \frac{\partial C(t, y, Y)}{\partial Y}>0 ; \frac{\partial C(t, y, Y)}{\partial t}<0 .
$$

Tax evasion is costly both because of the expected penalty to be caught and because hiding an ever growing income level is a more and more tricky activity (Cross and Shaw, 1982). The cost function is $K(r, y, Y)$, with

$$
K(r, 0, Y)=0 ; \frac{\partial K(r, y, Y)}{\partial y}>0 ; \frac{\partial K(r, y, Y)}{\partial r}>0 ; \frac{\partial K(r, y, Y)}{\partial Y}>0 .
$$


The household must solve the following problem:

$$
\left\{\begin{array}{cl}
\max _{y, L} & U(L, C(t, y, g(L, \alpha)))-K(r(\alpha), y, g(L, \alpha)) \\
\text { s.t. } & H(C(t, y, g(L, \alpha)))=0,
\end{array}\right.
$$

where $H=0$ is the budget constraint.

It is worth noting that the role of $y$ as decision variable does not contrast with the definition of $y$ provided in (2): indeed, the dependence of $y$ on the triple $(t, e, r)$ states simply that the decisions taken by the private sector are affected also on the institutional (exogenous) parameters $t, e, r$. More specifically, we hypothesize that taxpayers take $t, r, e, \alpha$ as given and that they are indifferent in paying the same amount of different combinations of taxes, expected penalties, license fees, and the like. Let us fix $t, e, \alpha \in[0,1]$ and assume that the functions $U, K$ and $H$ behave well, so that there exists a solution of the optimization problem (7) given by the couple $\left(y^{*}(t, e, r(\alpha)), L^{*}\right)$. The optimal level of output depends $^{7}$ on $\alpha$, and will be denoted as $Y^{*}=Y^{*}(\alpha)=g\left(L^{*}, \alpha\right)$.

How are $\alpha$ and $L^{*}$ related? From the macroeconomic point of view, Munnell (1992) has claimed that the correlation between $(1-\alpha)$ and $Y / L$ is positive. That is to say, for any given $Y, \alpha$ and $L^{*}$ are positively related. From the microeconomic standpoint, then, it has been argued that a lower $\alpha$ is associated to a bigger evasion. It, in turn, increases expected consumption for any given amount of leisure, this latter increases, and labor supply declines (Slemrod and Yitzhaki, 2002). Thus, once again, $L^{*}=L^{*}(\alpha)$ may be thought of as an increasing function of $\alpha$.

As for the optimal output level, it is a function of $\alpha$, i.e. $Y^{*}=Y^{*}(\alpha)=$ $g\left(L^{*}(\alpha), \alpha\right)$ and we assume that $Y^{*}$ and $\alpha$ are linked such a way to produce a Laffer-shaped curve, i.e. there exists $\bar{\alpha} \in(0,1)$ such that:

$$
\begin{cases}\frac{\partial g\left(L^{*}(\alpha), \alpha\right)}{\partial \alpha}>0, & \text { for } \alpha<\bar{\alpha} \\ \frac{\partial g\left(L^{*}(\alpha), \alpha\right)}{\partial \alpha}<0, & \text { for } \alpha>\bar{\alpha} \\ \frac{\partial g\left(L^{*}(\alpha), \alpha\right)}{\partial \alpha}=0, & \text { for } \alpha=\bar{\alpha}\end{cases}
$$

The rationale behind is that countries severely lacking in public capital (i.e. with a very high $\alpha$ ) or fiscal apparatuses (i.e. with a very low $\alpha$ ) are likely to have lower $\mathrm{Y}$ than those with less extreme situations. We now turn our

\footnotetext{
${ }^{7}$ See also the discussion in Acemoglu et al. (2005)
} 
attention to the links between $y^{*}$ and $t$. A logical, and traditional (Allingham and Sandmo, 1972), assumption is that the optimal undeclared income $y^{*}(t, e, r)$ is an increasing function of $t$. We postpone the discussion on the relationship between $y^{*}$ and the parameters $e$ and $r$ (or $\alpha$ ) to the next section.

As for the relationship between $Y^{*}, L^{*}$ and the tax rate $t$ we are able to prove that they are directly related. In fact, since $C$ is continuous and increasing with respect to $Y$ ceteris paribus, then it is also invertible, i.e. given $e$ and $\alpha$, there exists a function $R_{Y_{e, \alpha}}$ such that

$$
C_{t}^{*}=C\left(t, y^{*}(t, e, r(\alpha)), Y^{*}\right) \Leftrightarrow Y_{e, \alpha}^{*}=R_{Y_{e, \alpha}}\left(C_{t}^{*}\right) .
$$

Given $e, \alpha \in[0,1]$, we can write $Y_{e, \alpha}^{*}$ as a function of the tax rate as follows: $Y_{e, \alpha}^{*}=Y_{e, \alpha}^{*}(t)=R_{Y_{e, \alpha}}\left(C_{t}^{*}\right)$.

By the same token of equation (8), we write the lafferian relation between $Y_{e, \alpha}^{*}$ and $t$, i.e. there exists $\bar{t}_{e, \alpha} \in(0,1)$ such that

$$
\begin{cases}\frac{d Y_{e, \alpha}^{*}(t)}{d t}>0, & \text { for } t<\bar{t}_{e, \alpha} \\ \frac{d Y_{e, \alpha}^{*}(t)}{d t}<0, & \text { for } t>\bar{t}_{e, \alpha} \\ \frac{d Y_{e, \alpha}^{*}(t)}{d t}=0, & \text { for } t=\bar{t}_{e, \alpha}\end{cases}
$$

Furthermore, since $g$ in (3) is continuous and increasing with respect to $L$, then it is also invertible. For a fixed $\alpha \in[0,1]$, we denote $d_{\alpha}$ as the inverse of $g$ with respect to $L$ at the level $\alpha$, and write:

$$
Y_{e, \alpha}^{*}=g\left(L^{*}, \alpha\right) \quad \Leftrightarrow \quad L_{\alpha}^{*}=d_{\alpha}\left(Y_{e, \alpha}^{*}\right) .
$$

Equation (10) allows us to write $L^{*}$ as a function of $t$ : $L_{\alpha}^{*}=L_{\alpha}^{*}(t)=d_{\alpha}\left(Y_{e, \alpha}^{*}(t)\right)$.

\section{The State}

In our model, policymakers have two instruments to pursue one of two alternative targets. The government decides i) the tax rate and ii) the share of revenues devoted to fight the tax evasion rather than to increase the public capital in order to maximize either its revenues or the GDP. These goals should be seen as representative of the policies usually implemented in, respectively, social-democratic and capitalistic countries. We will show that, as expected, 
policymakers cannot maximize both $T$ and $Y$ contemporaneously. Another potential policy tool in our context is the level of regulation. We have chosen not to consider it as a device because, to some extent, the Bureau cannot afford to freely manage the level of regulations. In fact, as fairly noted by Glaeser and Shleifer (2003), the American and European societies are much richer today than they were a century ago, yet they are also vastly more regulated. The structural factor behind this is that modern good, financial and labor markets inevitably need regulations to protect weaker agents (respectively, consumers, savers and workers). The recent developments in financial markets and the following, strong, reaction of the Bureaus are an undisputable example of what we are talking about. Our model points out that there are threshold values activating non linear associations among the variables under scrutiny. In this section we explain the rich relationships between the involved variables from the ruler's standpoint, and how these connections affect the performances of $T$ - or $Y$-maximizing governments.

We model the quality of the institutional setting as depending on the levels of regulation, $e$, and the probability to be detected, $r$. Specifically, we define a function $a$ of the variables $e$ and $r$ such that $a(e, r)$ describes the institutional setting of a country with regulation level $e$ and probability of detection $r . a$ is a continuous function with respect to $e$ and $r$. Henceforth we use the convention that a country with institutional index $a_{1}$ has a weaker institutional setting than a country with institutional index $a_{2}$ if and only if $a_{1}<a_{2}$.

As already mentioned, there are reasons to think that $r$ is positively correlated with the efficiency of the Bureau. Thus, $a(e, r)$ is an increasing function of $r$. Moreover, since $r$ increases with respect to $\alpha$, then $a(e, r(\alpha))$ increases with respect to $\alpha$ as well. Therefore, $a$ is an invertible function of $\alpha$, and there exists an increasing function $b$ such that

$$
a=a(e, r(\alpha)) \quad \Leftrightarrow \quad \alpha=b(a) .
$$

In contrast, the behavior of $a$ with respect to $e$ is more complicated. The parameter $e$ is non linearly linked to the bureaucratic structure of the State. The idea is that both disorder $(e=0)$ and dictatorship $(e=1)$ are bad institutional settings. More in general, we claim that above a certain critical value of $e$ the government's activity becomes so intrusive ("from the cradle to the grave") that 
the Bureau just cannot avoid over-regulating. For instance, public goods and services might be offered at prices lower than the market ones, giving rise to an excess of demand that needs to be regulated. In addition, the government's size may trigger over-regulations simply to justify its own presence. So we assume that, for any $\alpha \in[0,1]$, the institutional index $a(e, r(\alpha))$ admits a global maximum in a critical threshold $e=\bar{e}_{\alpha} \in(0,1)$. More formally:

$$
\begin{cases}\frac{\partial a(e, r(\alpha))}{\partial e}>0, & \text { for } e<\bar{e}_{\alpha} \\ \frac{\partial a(e, r(\alpha))}{\partial e}<0, & \text { for } e>\bar{e}_{\alpha} \\ \frac{\partial a(e, r(\alpha))}{\partial e}=0, & \text { for } e=\bar{e}_{\alpha} .\end{cases}
$$

Substantially, relation (12) means that the maximum level of the institutional setting index can be obtained in countries with neither too light nor too heavy regulation frameworks.

The dependence of $y^{*}$ on regulation $e$ and on the probability of detection $r$ can be explicated through the institutional parameter $a$. To this end, we write $y^{*}(t, e, r)=y^{*}(t, a(e, r))$, assuming that $y^{*}$ decreases with respect to the institutional setting parameter $a$. Consequently, $y^{*}$ decreases as $\alpha$ increases. Finally, in view of the optimization problems assessed in the next section, we note that tax revenues can be written both as:

$$
T=t\left[\left(1-y^{*}\right) Y^{*}\right] .
$$

and as

$$
T=T(a, t) .
$$

Equation (13) includes one of the two policy instruments, namely the tax rate $t$ (the other is $\alpha$ ), and the three policy variables $\left(T, y^{*}\right.$, and $\left.Y^{*}\right)$ we are focusing on. In the following sections we will study how the instruments affect these variables. Finally, note that formula (14) emphasizes the relation between tax revenues, the institutional setting $(a)$ and the tax rate.

\subsection{The Optimizing State}

This section is devoted to the analysis of the two optimization problems faced by the State. 
The first goal consists in solving the following:

$$
\max _{t, \alpha} T(a(e, r(\alpha)), t) .
$$

In order to tackle the problem, we first analyze the behavior of the tax revenues with respect to both $t$ and $\alpha$.

Following the standard literature, there exists a threshold for the tax rate $\tilde{t}_{e, \alpha} \in$ $(0,1)$ such that:

$$
\begin{cases}\frac{\partial T(a(e, r(\alpha), t)}{\partial t}>0, & \text { for } t<\tilde{t}_{e, \alpha} \\ \frac{\partial T(a(e, r(\alpha), t)}{\partial t}<0, & \text { for } t>\tilde{t}_{e, \alpha} \\ \frac{\partial T(a(e, r(\alpha), t)}{\partial t}=0, & \text { for } t=\tilde{t}_{e, \alpha} .\end{cases}
$$

It is important to observe that (16) comes out from the model. Indeed we argue that, ceteris paribus, a change in the tax rate creates two opposite effects: i) the tax revenues $T(a(e, r(\alpha), t)$ increases linearly with respect to $t$ (see (13)); ii) the tax revenues are reverse U-shaped with respect to $t$, as (9) and (13) state. Formula (16) gives the usual Laffer-type relation between tax revenues and tax rate when the latter is stronger than the former.

Yet we also stress that, unlike the mainstream literature, condition (16) implies that the government revenues of a country with institutional parameter $a(e, r(\alpha))$ follow an institutions-conditional Laffer curve, $\tilde{t}_{e, \alpha}$ being the optimal Laffer tax rate. Now, consider $e, t \in[0,1]$. There exists a threshold $\underline{\alpha}$ such that:

$$
\begin{cases}\frac{\partial T(a(e, r(\alpha)), t)}{\partial \alpha}>0, & \text { for } \alpha<\underline{\alpha} ; \\ \frac{\partial T(a(e, r(\alpha)), t)}{\partial \alpha}<0, & \text { for } \alpha>\underline{\alpha} ; \\ \frac{\partial T(a(e, r(\alpha)), t)}{\partial \alpha}=0, & \text { for } \alpha=\underline{\alpha} .\end{cases}
$$

Even the relation (17) stems from the model. As, ceteris paribus, the parameter $\alpha$ changes, two contrasting behaviors emerge: i) tax revenues $T(a(e, r(\alpha)), t)$ are reverse U-shaped with respect to $\alpha$ (see eqs. (8) and (13)); ii) tax revenues increase, since $y^{*}$ decreases. Similarly to the previous reasoning, we argue that the former effect is more relevant than the latter, hence formula (17). An excessive $\alpha$, in fact, while reducing tax evasion also hampers the public capital accumulation and, hence, output. Due to the diminished taxable income, tax collection shrinks.

Remark 1. Due to the presence of the ceteris paribus positive effect of the tax rate on tax revenues, it is immediate to see that the threshold for the tax rate 
$\bar{t}_{e, \alpha} \in(0,1)$ defined in (9) cannot be greater than $\tilde{t}_{e, \alpha}$. By the same token, we have $\underline{\alpha}>\bar{\alpha}$, where $\bar{\alpha}$ is defined in (8). As we shall see, this outcome will turn out to be useful when comparing different policies.

Following the argument above, it also turns out that, if $a_{1}<a_{2}$, then $T\left(a_{1}, t\right)<T\left(a_{2}, t\right)$, for any $t \in(0,1]$.

The optimization problem (15) is then solved by the pair $\left(t^{*}, \alpha^{*}\right)=\left(\tilde{t}_{e, \underline{\alpha}}, \underline{\alpha}\right)$, i.e.:

$$
\max _{t, \alpha} T(a(e, r(\alpha)), t)=T\left(a\left(e, r\left(\alpha^{*}\right)\right), t^{*}\right)=T\left(a(e, r(\underline{\alpha})), \tilde{t}_{e, \underline{\alpha}}\right) .
$$

Let us now examine the second goal. By (3) and (10), the problem can be formalized as follows:

$$
\max _{t, \alpha} g\left(\alpha, L_{\alpha}^{*}(t)\right)
$$

The solution of the optimization problem (19) comes out from the analysis of the household's output. In this case, formulas (8) and (9) give that $Y^{*}$ is reverse U-shaped both with respect to both $t$ and $\alpha$. Therefore, the solution of the optimization problem is $\left(t^{*}, \alpha^{*}\right)=\left(\bar{t}_{e, \bar{\alpha}}, \bar{\alpha}\right)$, and we have:

$$
\max _{t, \alpha} g\left(\alpha, L_{\alpha}^{*}(t)\right)=g\left(\alpha^{*}, L_{\alpha^{*}}^{*}\left(t^{*}\right)\right)=g\left(\bar{t}_{e, \bar{\alpha}}, L_{\bar{\alpha}}^{*}\left(\bar{t}_{e, \bar{\alpha}}\right)\right)
$$

\subsection{Some Remarkable Results}

The optimization performed in the previous section allow us to emphasize some important features of our model.

Let us start from the analysis of the $T$-maximizing State.

The function $T$ is well-behaved so that we can explicitly describe how $e$ and $\underline{\alpha}$ affects the optimal tax rate $t^{*}$ in defining $\tilde{t}_{e, \underline{\alpha}}$. In fact, by applying the Implicit Function's Theorem (IFT), there exists a function $t^{*}=t^{*}(a)$ that is continuous and such that

$$
\frac{\partial T\left(a, t^{*}(a)\right)}{\partial t}=0, \quad \forall a \in \mathbf{R} .
$$

The IFT and equation (21) allow us to think of the Laffer optimal tax rate $t^{*}$ as a function of the institutional setting $a$. Following Friedman et al (2000), we assume that $t^{*}(a)$ is an increasing function. Also, conditional on any given $a$, we define the Laffer-optimal (maximum) revenue level $T_{a}^{*}:=T\left(a, t^{*}(a)\right)$. Since $T$ is positively related to $a$, then $T_{a}^{*}$ is increasing with respect to $a$ as well. 
We now limit the analysis to the situation in which a country, with an institutional setting $a$, levies the optimal tax rate $t^{*}(a)$ and reaches the maximum level of revenue $T_{a}^{*}$. Accordingly, the following analysis will be restricted to the optimal tax rate, $t=t^{*}$. It is worth noticing that we use this restriction only because in whichever point different from the lafferian top tax rate our results are simply reinforced. This said, we ask: what are the features of this peculiar "best case" fiscal framework?

- $T^{*}$ decreases with respect to the undeclared level of income $y^{*}$, as it naturally should be.

- Since $t^{*}=t^{*}(a)$ is continuous and increasing, then it is also invertible. Thus, there exists a function $k$ such that

$$
t^{*}=t^{*}(a) \quad \Leftrightarrow \quad a=k\left(t^{*}\right) .
$$

A standard analytical argument gives that $k$ is continuous and increasing. From (22) and since $t^{*}$ is increasing with respect to $a$, it turns out that only countries with a high-quality institutional setting can afford to impose a large optimal tax rate threshold $t^{*}(a)$. This is in line with the analysis by Friedman et al. (2000). Notwithstanding the high tax rate, this kind of Bureau enjoys a small optimal share of undeclared income because of the high expected penalty facing its taxpayers.

A further mathematical implication of the connections between $a$ and $y^{*}$ is the invertibility of $y^{*}$ as a function of $a$. There exists a decreasing function $m$ such that

$$
y^{*}=y^{*}\left(t^{*}(a), a\right) \quad \Leftrightarrow \quad a=m\left(y^{*}\right) .
$$

Condition (23) has a deep as well as logic significance: an increase in the share of undeclared income, $y^{*}$, worsens the institutional setting of a country.

This outcome is in stark contrast with the positive correlation between $t$ and $y^{*}$ highlighted by the standard approach to the tax evasion. In particular, as we will show, our theoretical model points out that for the maximum level of institutional setting, $\bar{a}$, the share of undeclared income is minimized. However, the institutional setting level $\bar{a}$ cannot be attained. As a consequence, the theoretical minimum level of undeclared income is outside the strategies available 
to the government. As such, it is not a practicable equilibrium of the economic system.

By the arguments explained above on the institutional setting parameter $a$, we are able to show that self-consistent, feasible, triplets do not allow to obtain a situation with zero tax evasion. We keep analyzing the "best case", that is the optimal lafferian State: $(t, \alpha)=\left(t^{*}, \alpha^{*}\right)$.

Fix $e \in[0,1]$ and define the function $f_{e}$ of the variable $\alpha$ such that

$$
f_{e}\left(\alpha^{*}\right)=T_{a\left(e, r\left(\alpha^{*}\right)\right)}^{*}=T\left(a\left(e, r\left(\alpha^{*}\right)\right), t^{*}\left(a\left(e, r\left(\alpha^{*}\right)\right)\right)\right) .
$$

As stated above, the optimal revenue $T_{a}^{*}$ is continuous and increasing with respect to $a$; moreover, $a=a\left(e, r\left(\alpha^{*}\right)\right)$ is a continuous and increasing function with respect to $\alpha^{*}$. Thus, the function $f_{e}$ defined in (24) is continuous and increasing, and this implies the existence of its inverse $Q_{e}$, that is continuous and increasing and works as follows:

$$
f_{e}\left(\alpha^{*}\right)=T_{a}^{*} \quad \Leftrightarrow \quad \alpha^{*}=q_{e}\left(T_{a}^{*}\right)
$$

Consider now the optimal regulation threshold defined implicitly in (12).

Fix $\alpha^{*} \in[0,1]$ and define the function $f_{1, \alpha^{*}}$ of the variable $e$ such that

$$
f_{1, \alpha^{*}}(e)=T_{a\left(e, r\left(\alpha^{*}\right)\right)}^{*}=T\left(a\left(e, r\left(\alpha^{*}\right)\right), t^{*}\left(a\left(e, r\left(\alpha^{*}\right)\right)\right)\right), \quad \forall e \in\left[0, \bar{e}_{\alpha^{*}}\right] .
$$

$T_{a}^{*}$ is continuous and increasing with respect to $a$ and $a=a\left(e, r\left(\alpha^{*}\right)\right)$ is continuous and increasing with respect to $e$ in $[0, \bar{e}]$. Thus, there exists its inverse $q_{1, \alpha^{*}}$ that is increasing and such that

$$
f_{1, \alpha^{*}}(e)=T_{a}^{*} \Leftrightarrow e=q_{1, \alpha^{*}}\left(T_{a}^{*}\right), \quad \forall T_{a}^{*} \in\left[T_{a\left(0, r\left(\alpha^{*}\right)\right)}^{*}, T_{a\left(\bar{e}_{\alpha^{*}}, r\left(\alpha^{*}\right)\right)}^{*}\right] .
$$

A very similar argument gives that, if we fix $\alpha^{*} \in[0,1]$ and define the function $f_{2, \alpha^{*}}$ of the variable $e$ such that

$$
f_{2, \alpha^{*}}(e)=T_{a\left(e, r\left(\alpha^{*}\right)\right)}^{*}=T\left(a\left(e, r\left(\alpha^{*}\right)\right), t^{*}\left(a\left(e, r\left(\alpha^{*}\right)\right)\right)\right), \quad \forall e \in\left[\bar{e}_{\alpha^{*}}, 1\right],
$$

then there exists a decreasing function $q_{2, \alpha^{*}}$ such that

$$
f_{2, \alpha^{*}}(e)=T_{a}^{*} \Leftrightarrow e=q_{2, \alpha^{*}}\left(T_{a}^{*}\right), \quad \forall T_{a}^{*} \in\left[T_{a\left(1, r\left(\alpha^{*}\right)\right)}^{*}, T_{a\left(\bar{e}_{\alpha^{*}}, r\left(\alpha^{*}\right)\right)}^{*}\right] .
$$

The true meaning of the formalized relations between Laffer-optimal revenues and regulations can be stated as follows: a greater level of revenues implies that 
a country spending $\alpha$ (to increase $r$ ) is improving its bureaucratic apparat so that $e$ is approaching $\bar{e}_{\alpha}$, i.e. the "Laffer-optimal" regulation level.

More importantly, the relationship between the couples $\left(T^{*}, \alpha^{*}\right)$ and $\left(T^{*}, e\right)$ formalized in (25), (27) and (29), allows us to state the existence of a relationship between $e$ and $\alpha^{*}$. Specifically, there exists a function $h$ such that $\alpha^{*}=h(e)$ and

$$
\begin{cases}h^{\prime}(e)>0, & \text { for } e<\bar{e}_{\alpha^{*}} \\ h^{\prime}(e)<0, & \text { for } e>\bar{e}_{\alpha^{*}} \\ h^{\prime}(e)=0, & \text { for } e=\bar{e}_{\alpha^{*}}\end{cases}
$$

Our model has important implications.

Next Proposition proves that the $T$-maximizing State has some constraints in choosing the share of public expenditure devoted to fight the tax evasion:

Proposition 2. The level $\alpha^{*}=1$ cannot be reached.

Another intriguing result of our analysis deals with the persistence properties, and the consequent ineluctability, of the tax evasion:

Proposition 3. Given $e \in[0,1]$, then

$$
y^{*}\left(t^{*}\left(a\left(e, r\left(\alpha^{*}\right)\right)\right), e, r\left(\alpha^{*}\right)\right)>0 .
$$

Let us now turn our attention to the output-maximizing State. In this case next Proposition will show that, starting from (20), the underground economy cannot be avoided:

Proposition 4. Given $e \in[0,1]$, then

$$
y^{*}\left(\bar{t}_{e, \bar{\alpha}}, e, r(\bar{\alpha})\right)>0 .
$$

Whichever the preferred target, then, another situation in which the tax evasion can be reduced to zero is when the ruler sets the tax rate equal to zero. Although clearly this is too extreme a case, our model allows to conceptualize it. If a country applies a tax rate $t=0$, then (22) gives that the institutional setting of the country is $a=g(0)$. Since $g$ is an increasing function, then $g(0)=\bar{a}=0$. As expected, $t=0$ is incompatible with functional values of the other variables of the model. Moreover, 
Remark 5. If the only aim of the State were to minimize the tax evasion, it should implement $t^{*}=0$ and/or $\alpha^{*}=1$. The former is unrealistic and the latter is impossible (see Proposition 2). This is a supporting argument to the unavoidability of the underground economy.

All in all, the State is not able to erase totally the tax evasion.

Finally, by Remark 1, we have that the tax rate which maximizes the output cannot be greater than the one maximizing the tax revenues. This fact implies that the fiscal policies that a country should implement to maximize the output are lighter than the ones useful for the maximization of the revenues.

Remark 6. Our model is able to conceptualize bad and good equilibria. The former are characterized by a low level of tax rate and institutional setting and a high level of tax evasion. Good equilibria, instead, are identified by a high level of tax rate and institutional setting, and a low level of tax evasion.

The arguments outlined in Remark 6 come out directly from the relationship between the variables $a, y^{*}$ and $t^{*}$. Specifically, formula (22) explains that $t^{*}$ and $a$ are positively correlated, while (23) states that $y^{*}$ and $a$ are negatively correlated.

\section{The Model and the Reality}

This section offers a simple attempt to see how our theoretical model is able to match the real world. In doing that we focus on two rich countries, likely lying in good equilibria and that differ with respect to their macroeconomic goals, namely revenues and output maximization. As mentioned, these goals could be seen as representative of the policies implemented in, respectively, socialdemocratic (say, Sweden, henceforth denoted with subscript 1) and capitalistic (say, the USA, henceforth denoted with subscript 2) countries.

Before going through the data, it is worth recalling that ours is a static general equilibrium model. Thus, what is important here is to see whether our theoretical suggestions match the systematic tendencies of data with no consideration about dynamics. ${ }^{8}$. The generality of our model is also mirrored in the

\footnotetext{
${ }^{8}$ For a recent example of a dynamic analysis dealing with the tax evasion, see Cerqueti and Coppier (2011).
} 
definitions of some of the variables we are dealing with. Just to mention, in our economy there is just one tax rate, the institutional setting may be thought of as including several (potentially strongly correlated) variables such as corruption, the rule of law and so on. This means that, hopefully, further (empirical and theoretical) analyses can stem from our model. Yet, there is an obvious trade off between the number of variables and the analytical tractability of a model. $^{9}$ Also, as already underlined, our main aim is the theoretical conceptualization, not the quantification, of the links between the variables. These latter, then, are non linear and, accordingly, not easy to examine by standard econometric tools. ${ }^{10}$ On the positive side, we can afford to compare just two economic systems. Obviously, it greatly simplifies the comparisons and reduces data problems. Finally, it should be clear that the less reliable data are, the greater is the need for the empirical analysis to be supported by sound theoretical indications. This said, we are eventually ready to see whether the real life situation matches the analytical structural prescriptions of the model.

According to our model, $t_{1}>t_{2}$. Indeed, the tax rates that a revenuesmaximizing country imposes on citizens is greater than the one imposed by an output-maximizing country, as Remark 1 shows. This result fits the evidence of a structurally larger tax rate in Sweden than in the USA. In Figure 1 the time series of the annual tax rates ${ }^{11}$ applied in Sweden and in the USA in the period 1990:2009 are plotted.

\section{INSERT FIGURE 1 ABOUT HERE}

Caption: $t_{1}$ (continuous line) is constantly greater than $t_{2}$ (dotted line)

Since $t_{1}>t_{2}$, our model states also that $a_{1}>a_{2}$. Indeed, relations (22) show that the institutional parameter $a$ increases with respect to $t$. This result is in line with both the common wisdom that a mature social democracy is featured by a top-quality institutional setting and qualitative data such as the World

\footnotetext{
${ }^{9}$ For instance, an intriguing improvement of our model could be inserting income distribution and/or, more explicitly, corruption in our framework. Hillman (2004) describes how corruption, akin tax evasion in our model, reduces tax revenues and affects economic development.

${ }^{10}$ This may explain the different results obtained by splitting world-wide samples as, e.g., in Friedman et al. (2000) with respect to Bovi and Dell'Anno (2010).

${ }^{11}$ Source: OECD
} 


\begin{tabular}{|c|c|c|c|c|c|c|}
\hline & 1990 & 1993 & 1995 & 1998 & 2000 & 2003 \\
\hline \hline$y_{1}$ & 18.8 & 20.5 & 24.2 & 24.8 & 23.8 & 22.4 \\
\hline$y_{2}$ & 7.2 & 8.9 & 9.6 & 9.8 & 9.5 & 9.2 \\
\hline
\end{tabular}

Table 1: The estimate of the shadow economy in Sweden and USA. Source: Bovi and Dell'Anno (2010).

Bank's "Indicators of Governance and Institutional Quality". ${ }^{12}$

Moreover, we also have that $\alpha_{1}>\alpha_{2}$. This result is grounded on $a_{1}>a_{2}$, by using the relations in (11). It sounds palatable and somewhat in line with the study by van der Weele on tax evasion (2009) - a country with very high statutory tax rates needs to check tax evasion more forcefully than a country where the taxpayers are not request to contribute so heavily.

Lastly, we have $L_{1}>L_{2}$. This finding is based on $\alpha_{1}>\alpha_{2}$, since $L$ increases with respect to $\alpha$. In fact, data shows that the employment rates in wellestablished social democracies are structurally larger than the ones recorded in capitalistic countries. Though ours is a theoretical model, we are nevertheless strongly tempted to speculate that this may be so due to well-functioning publicly-funded social infrastructures allowing, e.g., women to participate more actively in the labor market. This result is in line with the employment rates of the females in Sweden and in the USA. In Figure 2 the time series of the annual female employment rates ${ }^{13}$ in Sweden and in the USA in the period 1999:2009 are plotted - once again the structural indications of our model are mirrored in the trend of the data.

\section{INSERT FIGURE 2 ABOUT HERE}

Caption: $L_{1}$ (continuous line) is constantly greater than $L_{2}$ (dotted line)

Despite the availability of reliable data referring to hidden activities is almost by definition narrowed, some consideration based on the ranking appears reasonable. Specifically, figures say that $y_{1}>y_{2}$ (see Table 1 ).

On that, our model guarantees that the value of $y$ increases with respect to $t$ and decreases with $a$. Therefore, we argue that the legal tax rate in Sweden

\footnotetext{
${ }^{12}$ See http://www1.worldbank.org/publicsector/indicators.htm.

${ }^{13}$ Source: Eurostat.
} 
is so high that, in spite of the presence of very well functioning institutions, the Sweden's underground sector is tendencially larger than that of the USA. This finding is in line with both the classical theoretical prescriptions of Allingham and Sandmo (1972) and the empirical outcomes by Bovi and Dell'Anno (2010) that, like us, focus on rich economies.

Given the Laffer relations for $T$ with respect to $t$, and $Y$ with respect to $\alpha$, we are not able to theoretically conclude which is the greater between $T_{1} / Y_{1}$ and $T_{2} / Y_{2}$. Nonetheless, evidence suggests that $T_{1} / Y_{1}>T_{2} / Y_{2}$. This means that an increase in the legal tax rate has a greater negative impact on output than on the tax revenues when a country maximizes the tax revenues.

\section{Concluding Remarks}

The existing literature on tax evasion typically deals with its measurement, causes, consequences and remedies. Less analysed, at least explicitly, is the reason why the tax evasion is so persistent and how it impacts, given its longevity, on the long run macroeconomic performances of different economic systems.

This paper has exploited both traditional and recent indications to conceptualize the relationships between taxation, institutional setting and tax evasion. In doing that, and since tax evasion is a fact of life even in rich countries, this paper has focussed on the comparison between the macroeconomic performances of two well-established Bureaus - a social-democracy and a capitalistic country - which aim to maximize, respectively, fiscal revenues and GDP. The theoretical model is general and, as a consequence, it is robust to several specifications. Furthermore, it reconciles two important strands of research and it allows to examine a number of usually overlooked non linear "Laffer-type" connections. As per the comparison between economic systems, the model leads to the following results. Governments cannot be revenues- and GDP-maximizers at the same time and the effects of the tax evasion are different according to the different policy targets pursued by the State. As compared to GDP-maximizing states, then, revenues maximizing ones are featured by higher tax rates, more pervasive regulations and, consequently, from larger tax evasion despite they spend relatively more to contrast tax dodgers. On the other hand, revenues maximizing 
governments can afford to have better institutional settings and greater participation rates. This said, in no case the Bureau is able to erase totally the tax evasion, which may explain why this latter is so pervasive and persistent even in affluent economies i.e., in the words of the institutional literature, even in good equilibria. As a consequence, differently politically-oriented mature countries may not share the same good equilibrium that, accordingly, is not unique.

\section{References}

[1] Acemoglu, D, Johnson, S, Robinson, J, 2005. The Rise of Europe: Atlantic Trade, Institutional Change and Economic Growth. American Economic Review, 95(3); 546-579.

[2] Allingham M, Sandmo A, 1972. Income tax evasion: a theoretical analysis. Journal of Public Economics 1; 323-338.

[3] Barro, RJ, 1990. Government spending in a simple model of endogeneous growth. Journal of Political Economy, 98(5); 103-126.

[4] Bernardi, A, 1970. The Economic Problems of the Roman Empire at the Time of Its Decline. In Cipolla, C (Ed.) The Economic Decline of Empires, London: Methuen, 16-83.

[5] Bovi, M, Dell'Anno, R, 2010. The changing nature of the OECD shadow economy. Journal of Evolutionary Economics, 20(1); 19-48.

[6] Caballé, J, Panadés, J, 2000. Tax Evasion and Economic Growth. Public Finance / Finances Publiques, 52; 318-340.

[7] Cerqueti, R, Coppier, R, 2011. Corruption, tax evasion and economic growth, Economic Modelling, 28(1-2); 489-500.

[8] Cross, R, Shaw, GK, 1982. On the Economics of Tax Aversion. Public Finance, 37; 36-47.

[9] Cule, M, Fulton, M, 2009. Business culture and tax evasion: Why corruption and the unofficial economy can persist. Journal of Economic Behavior and Organization, 72(3); 811-822. 
[10] Frey, BS, Torgler, B, 2007. Tax morale and conditional cooperation. Journal of Comparative Economics, 35(1); 136-159.

[11] Friedman, E, Johnson, S, Kaufmann, D, Zoido-Lobaton, P, 2000. Dodging the Grabbing Hand: The Determinants of Unofficial Activity in 69 Countries. Journal of Public Economics, 76; 459-494.

[12] Glaeser, E, and Shleifer, A, 2003. The Rise of the Regulatory State. Journal of Economic Literature, 41; 401-25.

[13] Hanousek, J, Palda, F, 2004. Quality of Government Services and the Civic Duty to Pay Taxes in the Czech and Slovak Republics, and other Transition Countries. Kyklos, 57; 237-252.

[14] Hillman, AL, 2004. Corruption and public finance: an IMF perspective. European Journal of Political Economy, 20(4); 1067-1077.

[15] Hug, S, Spörri, F, 2011. Referendums, trust, and tax evasion. European Journal of Political Economy, 27(1); 120-131.

[16] Johnson, S, Kaufmann, D, Zoido-Lobaton, P, 1998. Regulatory Discretion and Corruption. American Economic Review, 88(2); 387-392.

[17] Johnson, S, Kaufmann, D, Zoido-Lobaton, P, 1999. Corruption, Public Finances and the Unofficial Economy, World Bank Working Paper N. 2169.

[18] Klepper, S, Nagin, D, 1989. The Anatomy of Tax Evasion. Journal of Law, Economics, \& Organization, 5(1); 1-24.

[19] Ihrig, J, Moe, KS, 2004. Lurking in the shadows: the informal sector and government policy. Journal of Development Economics, 73(2), 541-557.

[20] La Porta, R, Shleifer, A, 2008. The Unofficial Economy and Economic Development. Brookings Papers on Economic Activity, Fall 2008; 275-363.

[21] Lai, C-C, Chang, W-Y, 1988. Tax evasion and tax collections: an aggregate demand-aggregate supply analysis. Public Finance, 43; 138-146.

[22] Lai, C-C, Chang, J-J, Chang, W-Y, 1995. Tax evasion and efficient bargains. Public Finance, 50; 96-105. 
[23] Myles, G, Naylor, R, 1996. A model of tax evasion with group conformity and social customs. European Journal of Political Economy, 12; 4966.

[24] Mayshar, J, 1991. Taxation with Costly Administration. Scandinavian Journal of Economics, 93(1); 7588.

[25] Peacock, A, Shaw, GK, 1982. Tax evasion and tax revenue loss. Public Finance, 37; 269-278.

[26] Pommerehne, WW, Weck-Hannemann, H, 1996, Tax Rates, Tax Administration and Income Tax Evasion in Switzerland, Public Choice, 88; 161-170.

[27] Ricketts, M, 1984. On the simple macroeconomics of tax evasion: an elaboration of the Peacock-Shaw approach. Public Finance, 39; 420-424.

[28] Rosser, JB, Rosser, M, Ahmed, E, 2003. Multiple unofficial economy equilibria and income distribution dynamics in systemic transition. Journal of Post Keynesian Economics, 25; 425-447.

[29] Slemrod, J, Yitzhaki, S, 2002. Tax avoidance, evasion and administration. In: Auerbach, A, Feldstein, M (Eds.) Handbook of Public Economics, North-Holland, Amsterdam, 1423-1470.

[30] Slemrod, J, Yitzhaki, S, 1987. The Optimal Size of a Tax Collection Agency. Scandinavian Journal of Economics, 89(2); 2534.

[31] Turnovsky, SJ, Basher, MA, 2009. Fiscal policy and the structure of production in a two-sector developing economy. Journal of Development Economics, 88(2), 205-216.

[32] Van der Weele, J, 2009. The Signaling Power of Sanctions in Social Dilemmas. Journal of Law, Economics, \& Organization, doi:10.1093/jleo/ewp039.

[33] Von Zameck, W, 1989. Tax evasion and tax revenue loss: another elaboration of the Peacock-Shaw approach. Public Finance, 44; 308-315.

[34] Yitzhaki, S, 1974. A Note on Income Tax Evasion: A Theoretical Analysis. Journal of Public Economics, 3(2); 201-202. 


\section{Appendix}

Proof of Proposition 2. Let us fix $e \in[0,1]$ and assume $\alpha^{*}=1$. Formula (30) assures that $e=\bar{e}_{\alpha^{*}}=\bar{e}_{1}$. Hence we get $a\left(e, r\left(\alpha^{*}\right)\right)=a\left(\bar{e}_{1}, r(1)\right)=\bar{a}$. From (22) and since the tax rate is increasing with respect to the institutional setting parameter $a$, we have that $t^{*}=t^{*}(\bar{a})$ is the maximum level of lafferian tax rate. This means that the share of undeclared income $y^{*}\left(t^{*}\right)$ reaches its maximum level, since $y^{*}\left(t^{*}\right)$ is increasing. The analysis of the Laffer revenue $T^{*}$ points out that two inconciliable situations should coexist:

- $T^{*}$ must reach its maximum level as function of $t^{*}(\bar{a})$ (see formula $(16)$ ).

- $T^{*}=T^{*}\left(y^{*}\right)$ must reach its minimum level, since the level of the optimal Laffer revenue decreases with respect to $y^{*}$.

We have an evident contradiction.

Proof of Proposition 3. Let us fix $e \in[0,1]$ and assume $y^{*}=0$.

By (23), we derive that $a$ attains its maximum value $\bar{a}$, since it decreases with respect to $y^{*}$. Therefore, $t^{*}(\bar{a})$ is maximum, by using relation $(22)$. Since $y^{*}$ increases with respect to the tax rate, we have an evident contradiction.

Proof of Proposition 4. Let us fix $e \in[0,1]$ and assume $\alpha=\bar{\alpha}$ and $t=\bar{t}_{e, \bar{\alpha}}$. Since $y^{*}$ decreases with respect to $\alpha$, then

$$
0<y^{*}\left(\bar{t}_{e, \bar{\alpha}}, e, r(\alpha)\right)<y^{*}\left(\bar{t}_{e, \bar{\alpha}}, e, r(\bar{\alpha})\right), \quad \forall \alpha<\bar{\alpha},
$$

and the result is proved. 